\title{
Gramática, gramáticas y gramáticos. Algunas reflexiones teóricas sobre una experiencia docente
}

\section{Domingo Caballero}

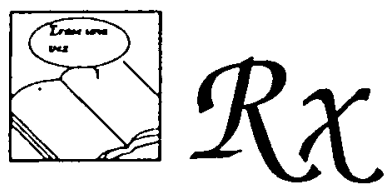

El autor narra aquí, con anécdotas, ejemplos y reflexiones tan concretas como cargadas conceptualmente, su aventura cotidiana como profesor de Lengua a la búsqueda de la verdad sobre el modelo y enfoque teórico-pedagógico que se debe aplicar entre los actualmente contendientes: el enfoque de la gramática formalista o el de los gramáticos «tradicionales». El resultado es quizá sorprendente y tiene implicaciones serias: el modelo tradicional ofrece mayor productividad, lo que el autor atribuye a que presta mayor atención - a su manera- al contexto. Esta presencia del contexto en los modelos tradicionales se presenta como el posible puente para conectar las actuales gramáticas pragmáticas y textuales -más prometedoras para el autor que las formales - con los modelos del lenguaje de la didáctica tradicional.

Hoy ya, tras la presentación de un programa semioficial como el que Jean Paul Bronckart ha trazado en el librito Las ciencias del lenguaje: ¿un desafío para la enseñanza? (Unesco, 1985), a saber: descubrir qué persigue la sociedad a través de la enseñanza del lenguaje; e insistir, en tanto que profesores, en la textualidad, la enunciación y la pragmática, la aventura que aqui vamos a relatar pudiera resultar una bistorieta didáctica anticuada. Sin embargo, es de temer que entre los formalismos de diverso signo y la realidad múltiple y psicosocial del lenguaje no se haya firmado la paz. 


\section{EL PASADO PASADO}

Acosados por la esterilidad didáctica de los estudios que sobre el verbo nos ofrecía cierto enfoque tradicional predominante, dedicamos algunas clases (corría la década de los setenta) con alumnos voluntarios de BUP y COU al tema del verbo.

Nuestros alumnos, a pesar de memorizar año tras año los mismos casilleros, parecían incapacitados para definir con coherencia los matices más elementales del verbo. Y decimos «definir»-exigencia escolar-; no "captar» - que esto sí puede realizarlo cualquier hijo de vecino.

Las causas pueden radicar en el fatal empirismo de cierta gramática tradicional que, ante la avalancha de datos y sutiles matices como los que el verbo exhibe, optó simplemente por ponerles nombre y tabularlos, de muy parecido modo al de las tablas de multiplicar, incluso tipográficamente. Es dudoso que la tabulación sea necesaria, pues un niño muy pequeño, a quien se le invite a deducir todas las personas de un tiempo dado, saldrá de la prueba bastante airoso. Lo que parece claro es que etiquetas tales como «pretérito perfecto» y "pluscuamperfecto», a ninguna parte conducen mientras no se le explique al alumno qué pueda significar «pretérito», qué «perfecto», o qué «plus».

Otra curiosa carencia de la tradición consistiría en la limitación de la enseñanza del verbo a los «tiempos», descuidando el «aspecto». Produce perplejidad el que se argumente que el aspecto posee un mayor grado de abstracción que el tiempo; y que es preferible dejarlo para ulteriores profundizaciones que, postergadas, nunca llegan.

La verdad es que un alumno capta, desde su experiencia lingüística, con bastante claridad, la diferencia entre un "comeré» y un "habré comido»; mientras que le resulta acaso más difícil la conceptualización de una categoría tenida por simple, como la del "potencial» clásico, entendido como "un futuro visto desde el pasado", etc.

En cualquier caso, sentíamos, como profesores, que la problemática fundamental pivotaba o bien sobre la necesidad tradicional de una gramática discreta, una gramática de elementos simples que luego se ajustan y ensamblan en un orden creciente de complejidad; o bien sobre la incuestionable realidad que lexemas y su definición léxica, tiempos, aspectos y relaciones múltiples entre todos ellos, parecen ser los que contribuye a definir y delimitar ese elemento simple.

Como didactas, queríamos controlar la potencia explicativa de los modelos en liza, desde el punto de vista de los alumnos.

\section{EL FUTURO PERFECTO}

Con esta apostólica intención, y en la duda inicial de echar mano, como guía básico, del clásico texto de Gili y Gaya o de los textos de Alarcos (ver bibliografía), optamos en un principio por Alarcos.

La terminología no era lo que nos arredraba, dado que, puestos a explicar desde la raíz el significado de "pretérito anterior» o de "pluscuamperfecto", lo mismo daba aclarar que "pretérito" significaría "pasado", o que "pluscuam-» significa «más que», que explicar que «remoto» significa también 
pasado, o que «prospectivo» remite a «futuro», o que «-spectar, -ivo» podría significar, grosso modo, «perspectiva-desde».

Una explicación para la cual Alarcos consumía no más de seis páginas parecía la más apta por sencilla. A estas aparentes ventajas habría que añadir nuestra profunda convicción, por aquellos tiempos, de que una visión formal era más omnicomprensiva y, por consiguiente, más científica que cualquier otra.

Simplicidad, no contradicción y omnicomprensión. He aquí el aprentemente irreprochable "principio de empirismo".

\section{LA IN'TENSIDAD DE LA EXTENSION}

En cualquier caso, si, por ejemplo, nos dedicamos a explicar al alumno el "modo" como "morfema extenso" (Alarcos, 1969, p. 109) parece necesaria, suficiente e iluminadora, la demarcación que este autor traza entre morfemas intensos y extensos. Héla aquí:

"Los morfemas extensos caracterizan una cadena de contenido de mayor extensión que el sintagma; a esta cadena se le llama nexo. Un nexo será una reunión de sitnagmas caracterizados como un todo por morfemas extensos. El concepto de nexo coincide aproximadamente con lo que se ha llamado "frase». Según esto, la denominación antigua de «morfemas verbales» carece de sentido; los morfemas extensos no caracterizan... al "verbo", sino a toda la frase (el nexo)». (Op. cit. p. 60.)

Pero el problema surge inmediatamente sobre qué sea «contenido de mayor extensión». Pues si acudimos a la conmutación sorprende que Alarcos considere que "su canto agradable» posee el mismo contenido de expresión que «él canta agradablemente» (ib. p. 61). Claro es que se trata de probar que la característica «-a» no caracteriza sólo a la base o lexema «cant-», sino a todo el nexo, a toda la oración.

De todos modos, nuestros alumnos observaban, a medida que avanzábamos en la explicación, y que recogíamos ejemplos y contraejemplos hablados o escritos, que el concepto de «extensión» o de «intensión» no presentaba bordes nítidos. Pues en «Sucedió durante el reinado de Juan Primero» la forma «durante» parece también extenderse tanto a "sucedió» como al resto de la frase.

Igualmente, en «Ojalá llueva el Día de la Constitución», «ojalá se hace extensible a todo el nexo, como una especie de infección semántica generalizada.

\section{"CONMUTANDO», QUE ES EXTENSO}

Cualquier gramática formal, en la medida en que obliga a una combinatoria constante mediante el arte de la conmutación, acentúa lúdicamente el carácter de puzzle que, a nivel formal, el lenguaje parece ostentar. Lo que, en ocasiones, garantiza cierta participación del alumno que, en la experiencia a la que nos venimos refiriendo, llegó a extremos afortunadamente jocosos, por el encarnizamiento en aportar ejemplos y contraejemplos.

El caso es que precisamente el general entusiasmo discente nos obligaba 
a salir constantemente de la explicación del paradigma estrictamente verbal; y a recorrer todos los caminos gramaticales y, lo que resultaba un tanto desconcertante (ver infra), los no gramaticales.

$Y$ es que llegaba un momento en que el concepto de extensión o no era productivo, o la conmutación no podía dar cuenta de un significado; o bien las deficiencias de la conmutación formal obligaban un tipo de conmutación decididamente contextual.

Pero lo más turbador de la experiencia era que lo contextual se convertía insensiblemente, y sin posibilidad de marcarle límites teóricos, en aquel concepto nefando que por aquel entonces empezaba a llamarse pragmática. Y todo ello para acabar hablando de "registros»; y constatar que tales registros eran quizá cortes sociales, además y acaso antes de serlo lingüísticos.

Volviendo a la extensión y al juego combinatorio.

Es sabido que las combinaciones y construcciones inaceptables pueden enseñar más sobre los contenidos gramaticales que los pacíficos ejemplos sin mácula.

Así, es posible decir «Mi profesor partió hacia Carrión de los Condes». También «Mi profesor partió a las cinco y media». Pero ¿por qué es inaceptable «Mi profesor partió durante un mes»?

Parece aceptable afirmar, con Alarcos, que «-ió» es un morfema extenso. Pero si «part-», lexema, es incompatible con el lexema «durante», parece claro también que algo hay en ese lexema "part-», algo «extensible» que impide ciertas combinaciones y rige otras. Si se decide que "partir» no es extensible más que en el caso de que se evite hacer referencias a la duración, entonces nos encontramos en plena semántica. Con lo que se nos hace sospechar de sopetón que resultaría imposible una morfosintaxis casi algebraica, tal como pretenden ciertos formalismos, a menos que se encuentre la manera de insertar la semántica desde el principio.

\section{EL CERO Y EL INFINITO}

Parecía desafortunada, pues, la conmutación de "su canto agradable» por «él canta agradablemente». No pueden poseer el mismo contenido; ya que, y utilizando los propios argumentos funcionalistas, un cambio de expresión debería provocar automáticamente un cambio de contenido.

No estamos empecinados aquí en una discusión académica. Es que sería penoso que, para probar un a priori, conmutemos lo que sabemos previamente conmutable. La discusión es fundamentalmente didáctica, pues la posibilidad de conmutación parece radicar más probablemente en el contexto y en las características semánticas de los elementos. $\mathrm{Y}$ en el aula no se construyen teorías; se conmuta reflexionando sobre lo que se dice o escribe.

En modo alguno se trata de negar el posible valor descriptivo y operativo de conceptos como intensión o extensión. Es claro que se podría contar con ellos para dar cuenta científica de los hechos de gramática. Pero nuestros alumnos y nosotros teníamos la impresión, más intensa cada vez, de que nuestro trabajo acaba situándose en un plano que era, en una medida difícil de determinar, vivo, coloquial, semántico, y hasta «antigramatical».

Por cierto, que en pocos casos aparece con mayor agresividad esta exigencia 
de atender al contenido y al contexto que en el concepto de «cero» (p. e. "Juan, $\emptyset$ idiota" frente a "Juan, eres idiota":

"Cuando la expresión de estos morfemas extensos no es cero, reaparece una base verbal, pero no añade ningún otro valor a la característica del nexo, sino el "énfasis». (Alarcos, op. cit., p. 69, subr. nuestro).

¿Pero no estamos en presencia de un nuevo contenido, precisamente el énfasis, al que denominar por su simple carencia sería puro formalismo abstracto? ¿Y no es más enfático, a fin de cuentas, en el mundo intersubjetivo, "Juan, idiota" que "Juan, eres idiota»?

Poseemos en castellano multitud de ejemplos de la serie apotégmica (con nexo habitualmente cero), son los famosos refranes.

Como era de esperar, alumnos y profesores nos apoyamos en ellos para intentar probarnos que la extensión no necesitaría base, tal como Alarcos afirma en la cita anterior. Mas pronto caímos en la cuenta de que si se dice /«mal de muchos, consuelo de tontos»/variaba realmente el contenido respecto a /«el mal de muchos es el consuelo de los tontos»/.

En primer lugar porque la variante / «mal de muchos es consuelo de rontos»/ a muchos les traía, sin saber muy bien por qué, efluvios de registro más formalmente literario. Pero ese registro está claro que ya no es en sí mismo un contenido. $\mathrm{Y}$, en segundo lugar, porque la expresión apotégmica pura también conlleva un contenido que le es propio como "género». Estos contenidos no parecen nacer de una carencia (la de «es»), sino que son en sí mismos una presencia, y muy determinada socialmente y culturalmente por cierto (refrán: ruralismo, sabiduría "popular» contradictoria, concisión, organización, cuasi-estrófica para la memorización por vía oral, etc.).

\section{LA ESTRUCTURA CONTRA EL SENTIDO}

Para ser breves diremos que éstos y otros muchos casos nos remitieron a otros textos teórico-normativos no inspirados por el formalismo, a fin de hacernos con unos principios didácticos más apropiados.

Tal puede ser el caso del "Curso superior de sintaxis española», de Samuel Gili y Gaya, donde pueden leerse asertos del siguiente tenor:

«El aspecto perfectivo o imperfectivo de una acción depende conjuntamente del significado del verbo, de la forma temporal empleada y del complemento que le acompaña» (op. cit. p. 100).

Gaya parece desdeñar cierto tipo de lógica formal, pero recurriendo constantemente a explicaciones que algunos, desdeñosamente, tildarían de psicologicistas.

$\mathrm{Y}$ nos resultaba personalmente escandaloso y un punto anticientífico, acostumbrados como estábamos a concebir lo psicológico en lingüística como una pantanosa subjetividad.

Se trataba de una cierta apelación a la conciencia lingüística del hablante, terreno movedizo del "habla», donde las categorías estallan, se fragmentan y entrecruzan. 
Una afirmación como la de Gaya:

"El contexto y la situación del hablante desempeñan papel decisivo en la medición de los tiempos relativos, y por sí solos pueden suplir a las conexiones estrictamente gramaticales... la división en tiempos absolutos y relativos no debe entenderse con demasiado rigor, como si se tratara de una clasificación en que los miembros clasificados se excluyen entre sí. Es sólo una guía aproximada...” (op. cit., pp. 151-152, subr. nuestros)

constituye la negación explícita de cualquier formalismo, una mezcolanza de categorías laxas, insultante para un formalista aguerrido.

$\mathrm{Y}$, sin embargo, bajo la sombra de esta batuta los alumnos aprendieron más sobre el verbo; se replantearon con orden muchas dudas. Mientras que nuestra propuesta inicial les había llevado a plantearse preguntas, sí, pero sin respuesta dentro de la lógica interna del sistema.

\section{"LOS ERRORES SIEMPRE SE DAN POR PAREJAS»"}

De universitarios flamantes pasados por la docencia nos veíamos ahora como perplejos profesores con ganas de dar un repaso a la institución universitaria. Las dudas se nos hacían más acuciantes, más didácticas, más prácticas; pero también más científicas.

Así, si nos ateníamos al «modo», el binarismo apuntado por Alarcos: "realización/no realización»; o «realización deseada/no deseada», para caracterizar la diferencia entre indicativo y subjuntivo, destilaban de inmediato la duda de si ahora la «realización» y el «deseo"no eran una introducción espúrea de conceptos indignos del formalismo, por psicologistas y subjetivos.

La suposición venía abonada por la dificultad de encajar en este esquema binario «à quatre» conceptos tales como temor, ignorancia, emoción, ecesidad subjetiva u objetiva, posibilidad, etc. Tratar de encajarlos en algún tipo de esquemas, y más si es por parejas, si es obligatoriamente binario, conduce a discusiones sin salida; como saber si los verbos de «temor» son reducibles a la «no realidad», aunque lo que se tema pueda no ser real. O cómo encajar la «duda» en «realización no deseada».

\section{GILI Y GAYA, ALARCOS Y ZENON}

Ya venimos diciendo que Gaya parece incurrir constantemente en psicologismo:

«Entre la afirmación y la negación, pasando por la duda absoluta, hay una gradación indefinible, de la cual es signo linguístico, para el que habla y para el que escucha, el modo en que cada caso se prefiera...» (op. cit., p. 135, sub. nuestro).

No se trata ahora de dilucidar si ser psicologista pudiera ser un insulto. Simplemente constatar que lo que se desprende de estas confrontaciones teóricas no es, ni más ni menos, que la vieja cuestión de si lo gradual (la vida misma) es formalizable en parejas binarias.

Desde Zenón se comenta que lo que podríamos llamar «matices" son 
infinitamente divisibles, por ser el matiz la expresión de la gradualidad de un continuum.

Concretamente, si quisiéramos dar cuenta exhaustiva de los matices sin negar el binarismo, tendríamos que recurrir, para redefinir los modos indicativo y subjuntivo, a rasgos que rebasan con mucho la "realidad» y el «deseo".

Así, quizás habría que definir el indicativo, en ciertos casos, como una compleja mezcla de «afirmación-subodinada-más-certidumbre»; o el subjuntivo como algo parecido a «ignorancia-más-incertidumbre, etc.».

No bastaría, pues, con una o dos parejas de oposiciones; sino que quizás fueran necesarias hasta varias docenas, opuestas a su vez entre sí, a lo que habría que añadir «matices» de oposición, generándose una fantástica e indescriptible complejidad.

A mayor abundamiento, semejante pirotecnia, en la que la realidad hablada desbordaba todas las costuras categoriales, no dependía la mayoría de las veces de una categoría, sino del significado léxico y contextual.

\section{CUANDO TODOS LOS TIEMPOS SON PARDOS}

Para no alargar lo que no desea ser otra cosa que un ejemplo docente, pasaremos de puntillas por el concepto de «tiempo»; en el cual, desde perspectivas formales, nos toparíamos con parecidas perplejidades.

Así, parecía imposible dar cuenta cumplida del "tiempo" a base del binarismo «remoto/irremoto» y "prospectivo/improspectivo" (grosso modo: realizado o no, y futuro o no).

Aunque aquí la terminología adoptada, merced a un guiño académico, pretenda eludir conceptos resbaladizos como "futuro», "pasado», «durativo», a fin de no ensuciarse las manos con lo psicológico, tampoco acaba de conseguirlo. Y quizá se deba a que «lo momentáneo, durativo, reiterativo, incoativo o perfectivo..." a más de ser una cuestión eminentemente léxica en muchos casos (Gili y Gaya, op. cit. p. 147), en otros es lo morfológico lo que produce esos efectos, efectos de lo que parecía no poder dar cuenta la idea simple de "prospectivo", "remoto", etc.

$\mathrm{Y}$ hay más. Si del "aspecto" se trataba, al que Alarcos también acoge como categoría formal perfectamente aislable, advertíamos que, en muchos casos:

«...en el carácter perfectivo o imperfectivo de una acción concreta, influye tanto el tiempo en que se halla el verbo como su significado" (Gaya, ib. p. 148, s. nuestro).

En fin. La experiencia a la que me vengo refiriendo, y que probablemente no produjo, para su fortuna, tan sesudas reflexiones en nuestros alumnos, se resume cumplidamente en esta afirmación de Gili y Gaya, que no sabríamos si es una afirmación pre-estructural históricamente, o anti-estructural: 


\section{LOGICA DISTINGUIDA Y LOGICA POPULACHERA}

Parecería que existe un principio pedagógico inatacable: que hay que ir de lo simple a lo complicado.

Pero ya no parece tan seguro que las oraciones «simples» sean del tipo oficial y de librillo de texto que todos conocemos. Y que, caso curioso, estén ejemplificadas de muy parecido modo en gramáticas de muy diferente obediencia teórica.

Las oraciones simples (dejemos a los genetistas el juicio final) semejan ser del tipo «aquí, chaval», o "tira, Pepa». La mayoría de los gramáticos responden a este reto defendiendo que hay que efectuar una serie de operaciones - «lógicas» por supuesto- para explicarlas gramaticalmente. No existe seguridad de que el hablante realice tales operaciones, pero los gramáticos se empeñan en hacerlas por él.

Pero hay más: Se puede objetar que este tipo de oraciones «corrientes» pueden prescindir de la lógica lineal porque el contexto les confiere su propia lógica. Si así fuere (y pasando por alto la pintoresca afirmación de que el hablante prescindiría en ocasiones de la lógica. ¿Qué lógica?), concluiremos que existe un lenguaje, el ESCRITO, que, al darse en ausencia del contexto, necesita una organización distinta de sus elementos.

La sospecha de que en el mundo de la cultura (el de la escuela y la gramática oficial) la ecuación LOGICA = LENGUAJE ESCRITO es una hipótesis intocable. $\mathrm{O}$, dicho de otro modo, que el lenguaje escrito es el paradigma del «lenguaje», y que toda otra manifestación del lenguaje no puede ser abordada más que desde el lenguaje escrito, arrastra todo género de consecuencias, las cuales habría que someter a severo análisis.

Sea lo que fuere, parece que los gramáticos de todas las obediencias tienden a juzgar el «habla» con el rasero del lenguaje escrito, e incluso únicamente con cierto lenguaje escrito que se denomina, tautológicamente, gramatical. ¿ڤo sería legítima la sospecha de que la misma gramática crea el lenguaje gramatical?

\section{HABLAR COMO UN LIBRO}

Se comprenderá que, cuando las dudas chisporrotean hasta estos grados, se está en vísperas de un asalto global a la cultura lingüística recibida.

No basta con cantar las excelencias del lenguaje escrito como momento estelar de la humanidad y cumbre de la razón. O como comunicación diferida $y$, en consecuencia, necesitada de apoyaturas lógicas.

Desde esta postura se trataría de probar que es la separación del contexto lo que haría que el habla escrita sea una hazaña humana por un lado; y, por otro, el puesto privilegiado de observación para analizar el habla en general. Cuando más bien parece que la separación del contexto es quizá un eufemismo traducible como separación de la práctica bumana. Lo cual es grave, y deja entrever unos puntos de partida sospechosos; unos puntos de partida que enfocan primero el habla como «institución social», para después normativizarla a medida de una Subinstitución tan minoritaria como es el habla escrita y como lo son los grupos que la usan preferentemente.

Pues, en efecto, todos los textos insisten en que, para bien hablar y bien escribir, es necesaria la lectura asidua de los tautológicos «buenos» escritores. 
No se trata de hacer demagogia sobre la comunicación diferida, catalogándola como "privilegio de unos pocos», etc.

Se trata de preguntarse muy científicamente el porqué de la falta de necesidad que la mayoría de los ciudadanos ostenta ante tal tipo de «comunicación".

\section{IMANENCIA FORMAL FRENTE A TRANSCENDENCIA SOCIOLINGÜISTICA}

Es, evidentemente, imposible hacer ciencia sin la elaboración laboriosa de categorías, abstracciones y formalizaciones. Parece asumido que lo concreto no existe a menos que se entienda como un depósito de abstracciones. Por ese lado el estructuralismo no debía plantearnos problemas.

Es más, teníamos y tenemos una cierta seguridad de que sólo una visión formal matizada pueda dar cuenta de la realidad. El problema estaba, y sigue estando, en el tipo de estructura que se construye, y en los «a prioris» de que se parta.

En el caso al que nos estamos refiriendo: el del verbo en castellano, poseíamos la brillante formalización de Alarcos. Aparentemente se trataba de una explicación simple y omnicomprensiva; pero, al contacto con la realidad del aula y del habla, se observaba que no podía comprehenderlo todo. Como esto era así, se imponía complejificar la explicación, con lo que dejaba de ser simple. Achaque éste general a todos los formalismos lingüísticos.

Por el contrario, Gili y Gaya ni es el representante de una gramática normativa estricta, ni tampoco puede decirse que se sumerja en una casuística incontrolada. Y el uso de su metodología implícita permitió conseguir de los alumnos una movilidad mental no agarrotada por formalizaciones, y capaz de abordar cualquier «imprevisto».

Ahora bien. Hoy ya hay mucha gente que piensa que tanto la semántica léxica como la situación psicosociolingüística del hablante, pueden y deben ser considerados como «contenido». Lo que sucedía es que no disponíamos de un mecanismo de unión entre el contenido como sustancia (las culturas) y el contenido como forma (los lenguajes).

Mas no sólo la solitaria reflexión docente, sino sobre todo la pública $y$ cotidiana experiencia discente, demuestran que el hablante no es capaz de interpretar, ni mucho menos de producir, un esquema morfosintáctico correcto cuando desconoce las condiciones de uso social y cultural de un contenido de la cadena.

Es más. Hasta una simple posición insólita de contenidos conocidos impide esa comprensión.

La eterna, aburrida, silenciosa, agresiva o indiferente protesta de los alumnos de que «no entienden». Ni lo que decía Berceo, ni lo que dice un periódico local, tendería a abonar obsesivamente en nosotros la idea de que sólo una sociosemántica podría ser la clave teórica y didáctica del habla.

Esa sociosemántica es implícitamente manejada por gramáticos «tradicionales" como Gaya o Bello. Y quizá ésta sea la clave de que conecten más con nuestros temores y esperanzas docentes. 
Se trata de una afirmación arriesgada: Afirmar paladinamente que Bello y Gaya (yo añadiría a Capmany) son unos gramáticos adscritos clandestinamente a la sociosemántica sería, además de un anacronismo, una majadería.

Lo que sucede es que los buenos gramáticos tradicionales ejemplifican tomando sus ejemplos y contraejemplos de esa zona intermedia entre lo literario y lo «correcto", sin desdeñar a veces lo coloquial. Su corpus abarca, pues, una gran variedad de estratos, superando los acartonados ejemplos ad hoc de las gramáticas formales, las cuales, en ocasiones, sólo parecen hablar de sí mismas, pero no del lenguaje.

Por otro lado, y por la misma razón, los «tradicionales» conmutan más con contextos que con otras formalidades previas.

A fin de cuentas los alumnos (y nosotros) no somos sujetos puros lingüísticos. Sino sujetos intersubjetivos, es decir, sujetos psicosociolingüísticos.

\section{Notas}

' Carlos Lerena, «Reprimir y liberar», Akal, 1983. In memoriam, agosto, 1988.

\section{Bibliografía anotada}

Por supuesto, detrás de la armazón teórica de estas reflexiones actuales, están latiendo otras lecturas e incitaciones recientes, que el lector podrá reconocer:

Kress, G. y Hodge, R.: Language as Ideology, Londres, Routledge and Keagan Paul, 1979. Fowler, R.: La literatura como discurso social, Alcoy, Marfil, 1988.

Hall.idday, M. A. K.: El lenguaje como semiótica social, trad. México, F.C.E., 1986, 2..

[Kress, Fowler y Halliday muestran hasta qué punto gramática y sociología se imbrican.]

Delamont. S.: La interacción didáctica, Madrid, Cincel, 1984.

Foucault, M.: Microfisica del poder, Madrid, La Piqueta, 1980.

APPLE, M.: Maestros y textos, Madrid, Paidós-MEC, 1989.

[Foucault, Apple y Delamont pueden ilustrar sobre el modo en que la enseñanza consiste en una forma de poder político a través del lenguaje.]

Bourdieu. P.: La distinction, París, Minuit, 1979.

[Este autor nos indica en qué se invierte, y para qué, y para quiénes, el «capital cultural».]

BALIBAR, R. y LAPORTE, D.: Le français national, trad. Burguesía y lengua nacional, Barcelona Avance, 1976.

[Nos convencen de hasta qué extremos pudieran estar atrasadas las universidades vernáculas; en consecuencia los profesores, y, en consecuencia, los libros de texto].

Alarcos Llorach, E.: Gramática éstructural,' Madrid, 'Gredos, 1969.

Alarcos Llorach, E.: Estudios de gramática funcional, Madrid, Gredos, 1972.

Bello, A.: Gramática, Introducción y notas de R. Trujillo, Madrid, Arco-Libros, S. A., 1988.

Bronckart, J. P.: Las ciencias del lenguaje: ¿un desafio para la enseñanza?, Lausana, Presses Centrales, Unesco, 1985.

Gil.i y GAya, S.: Curso superior de sintaxis española, Madrid, Vox, 1964, 9..

[Nos desvelan cómo, incluso tras la sintaxis, se ocultan ideologías].

Culler. Fish, Derrida. Jameson. Pratt: La lingǘstica de la escritura, trad. Madrid, Visor, 1989. 


\section{Gramática, gramáticas y gramáticos (Algunas reflexiones teóricas sobre una experiencia docente).}

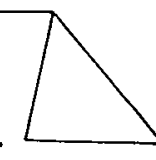
D. Caballero.

\section{CLEE, 1991, 9, pp. 33-43}

Resumen: De la comparación entre los gramáticos formalistas modernos y los gramáticos "tradicionales", psicologicistas o eclécticos, surge la sorpresa de una mayor productividad didáctica de estos últimos. Se defiende aqui que la atención a un cierto contexto de los "tradicionales" sería, por un lado, la clave de su mayor éxito para un uso pedagógico; $y$, por otro, un buen punto de partida para conectar con las actuales gramáticas pragmáticas y textuales, en nuestra opinión más potentes descriptiva y didácticamente que las formales.

Datos sobre el autor: Domingo Caballero es Catedrático de Bachillerato en Lengua y Literatura, Doctor en Psicología Social y Experto Universitario en Didáctica específica (U. Complutense).

Dirección: Instituto de Bachillerato «Victorio Macho», Los Trigales, s/n. Palencia.

๑ de todos los artículos. Deberá solicitarse por escrito autorización de CL\&E para el uso en forma de facsímil, fotocopia o cualquier otro medio de reproducción. CL\&E se reserva el derecho de interponer las acciones legales necesarias en aquellos casos en que se contravenga la ley de derechos de autor. 